\title{
Response Relationship between the Seasonal Freezing-Thawing Process of Soil and Spatial Factor Changes in the Dayekou Basin of the Qilian Mountains
}

\author{
Yun Niu1, Jinling An ${ }^{2 *}$ \\ ${ }^{1}$ School of Urban and Environmental Science, Huaiyin Normal University, Huaian, China \\ ${ }^{2}$ Administration of Qilian Mountain National Nature Conservation in Gansu, Zhangye, China \\ Email: ^1053803929@qq.com
}

How to cite this paper: Niu, Y. and An, J.L. (2018) Response Relationship between the Seasonal Freezing-Thawing Process of Soil and Spatial Factor Changes in the Dayekou Basin of the Qilian Mountains. Open Journal of Ecology, 8, 417-431. https://doi.org/10.4236/oje.2018.88025

Received: March 11, 2018

Accepted: August 7, 2018

Published: August 10, 2018

Copyright @ 2018 by authors and Scientific Research Publishing Inc. This work is licensed under the Creative Commons Attribution International License (CC BY 4.0).

http://creativecommons.org/licenses/by/4.0/

(c) (i) Open Access

\begin{abstract}
Objective: In this study, the influence and response relationship between the seasonal freezing-thawing process of soil and the spatial factor changes in the management and utilization of water resource processes were explored. Methods: The monitoring equipment in this study was arranged at different altitudes, gradients, and slope directions, such as the typical forest sample area in the Dayekou Basin of the Qilian Mountains. The spatial variation characteristics of the seasonal freezing-thawing process of the soil were analyzed, and a regression model was established. Results: 1) The results of this study determined that the rate of the soil's freezing increased with the altitude in a trend of volatility. However, the rate of the thawing of the frozen soil was found to have an opposite trend. The variation degree of the freezing-thawing process increased with the altitude in a trend of volatility. The end time of the approximate soil freezing with altitude increased in a volatility trend ahead of schedule. However, the opposite was observed in the thawing rate of the frozen soil; 2) The rate of the soil's freezing under the mosses of the spruce forest at an altitude of $3028 \mathrm{~m}$ was found to be the lowest. However, in the sub-alpine scrub forest at an altitude of $3300 \mathrm{~m}$, a maximum in the spatial ordering was observed, with an average of $1.9 \mathrm{~cm} \cdot \mathrm{d}^{-1}$. The thawing rate of the frozen soil in scrub-spruce forest at an altitude of $3300 \mathrm{~m}$ was found to be minimal. However, in the sunny slope grassland at an altitude of $2946 \mathrm{~m}$, a maximum in the spatial ordering was observed, with an average of $1.5 \mathrm{~cm} \cdot \mathrm{d}^{-1}$. In the spatial ordering of the variation degree of the process of freezing-thawing with an average of 1.2, the scrub-grassland at an altitude of 2518
\end{abstract}

${ }^{*}$ Communication author: AN Jinling, Senior Engineer of Administration of Qilian Mountain National Nature Conservation in Gansu, Zhangye, Gansu 734000, China. 
$\mathrm{m}$ was found to be the lowest, and the scrub-spruce forest at an altitude of $3195 \mathrm{~m}$ was also low; 3) The soil freezing began on approximately October $20^{\text {th }}$, and the rate of soil freezing gradually became reduced. The arrival time of the frozen soil of up to $150 \mathrm{~cm}$ in depth in sub-alpine scrub forest was first observed at an altitude of $3028 \mathrm{~m}$. However, the scrub-spruce forest at an altitude of $3100 \mathrm{~m}$ did not become frozen until approximately January $12^{\text {th }}$ on average. Then, the thawing rate of the frozen soil increased gradually. The end time of the thawing was earliest observed in the sunny slope grassland at an altitude of $2946 \mathrm{~m}$. However, the scrub-spruce forest at an altitude of 3100 $\mathrm{m}$ was found to be the last to thaw, and averaged approximately July $27^{\text {th }}$. The average durations of the freezing and thawing of the soil were 77 and 121 days, respectively, and the average duration of the entire process of freezing-thawing was 199 days; 4) This study's established regression models of the duration time of frozen soil's thaw, and the rate of frozen soil's thaw, all passed the $R$ test of goodness of fit, $F$ test of variance, and $t$ test. Conclusions: The characteristics of the seasonal freezing-thawing process of the soil with the spatial changes were seasonal. However, the characteristics under the different spatial factor influences were not the same.

\section{Keywords}

Freezing-Thawing, Spatial Factor, Seasonal Frozen Soil, Dayekou Basin of the Qilian Mountains

\section{Introduction}

The frozen earth changes are the main research content of a cryosphere, and the freezing-thawing process of soil directly affects basin runoff. It is known that, within a basin, the freezing-thawing process of soil tends to be sensitive to spatial changes. Therefore, in order to explore the basin runoff process, the spatial variation attributes of the freezing-thawing process of soil should be considered [1] [2]. One of the most important and difficult problems in frozen earth research is the determination of the spatial changes of the frozen earth, especially those on a basin scale [3]. The previous research regarding the spatial changes of frozen earth has mainly concentrated on three aspects. One aspect is the assumption of the future climate scenarios, considering that plateau regions are generally warming with the same amplitude, and permafrost degradation is known to occur not only on the edge of the permafrost zone, but also around the valley thawing area, and the high plain swamp in the permafrost regions [4] [5] [6]. The second aspect is the speculation of the spatial changes of the permafrost in the limited areas using the drilling or cutting data at limited points [7]. The third aspect of main research content is the spatial changes of the permafrost, or the seasonal frozen soil in the Qinghai-Tibet Plateau [8]. These research results have important academic and application values. However, there have been few- 
er experiments conducted regarding the massive measured data of the spatial variation factors on a basin scale which can be utilized for the studying of the freezing-thawing process of soil.

The Qilian Mountain is located on an intersection of three plateaus (i.e. the Qinghai-Tibet, Inner Mongolia-Xinjiang and Loess Plateaus), and has a very important geographic position in national forest hydrology and ecology research. A combination of the soil's freezing-thawing hydrologic process as an inevitable hydrological phenomenon in this region, and the insufficient related research, has made it very necessary to carry out related research in this region. During the research regarding the spatial changes of the frozen soil in the Qilian Mountains or upstream of the Heihe River, seven thermometer boreholes were used to set thermometer tubes for ground temperature monitoring for the purpose of studying the frozen soil distribution characteristics [9]. More than 40 years of temperature and soil temperature data at a depth of $5 \mathrm{~cm}$ from $11 \mathrm{me}$ teorological stations were adopted to systematically study the monthly seasonal frozen soil distribution from 2000 to 2009, along with the spatiotemporal variation characteristics of the freezing probability [10]. Based on an elevation-response model, the high-resolution elevation data (DEM), longitude data, latitude data, annual average air temperature (MAAT), and vertical lapse rate data (VLRT) were applied for a numerical simulation of the frozen earth distribution in the Qilian Mountains during the last 40 years [11]. Related research has also been conducted in the Sidalong, Binggou, and Pailugou Basins of the Qilian Mountains by the Gansu Research Institute of Water Conservation Forest in the Qilian Mountains [1] [12] [13] [14]. This research focused on the hydrological and inter-annual change characteristics of the freezing and thawing process of soil.

In summary, there were few experimental results available to set the denser sample plots and frozen soil tubes in the basin for the long-term field monitoring of the frozen soil changes. There was also only a small amount of data regarding the changes in the spatial factors such as altitude, slope gradient, slope direction, and crown density factors, by which to study the freezing-thawing process of soil. Accordingly, the monitoring devices were set in typical sample plots with different elevations, slope gradients, slope directions, and forest stands throughout the entire basin to obtain the data for this study. The spatial variation characteristics of the soil's freezing and thawing processes were analyzed to further resolve the stand structure of the basin, along with its function mechanism of water conservation, which provided a scientific basis and reference for the ecological hydrology.

\section{Study Area}

The Qilian Mountains are located at the intersection of the Qinghai-Tibet, Inner Mongolia-Xinjiang and Loess Plateaus. This mountain range is classified as one of 50 nationally important eco-function areas, and one of 25 key eco-function 
areas by the National Ecological Function Regionalization and the National Major Function Area Planning, and thereby presents a very important ecological niche. The Dayekou Basin $\left(38^{\circ} 16^{\prime} \mathrm{N}-38^{\circ} 33^{\prime} \mathrm{N}, 100^{\circ} 13^{\prime} \mathrm{E}-100^{\circ} 16^{\prime} \mathrm{E}\right)$ belongs to the Zhongshan climate zone of the Qilian Mountains, and extends East to Mazongliang, West to Xigouliang, North to Zhengnangou, and South to Pailugou. This basin originated from Yeniu Mountains, Sunan County. Six larger branches, namely Dongcha, Xicha, Toutangou, Xigouliang, Guantaigou and Shengou, converge at the Dayekou Reservoir, with an area of $80 \mathrm{~km}^{2}$, and control $98 \%$ of the basin catchment area, which indicates a typical closed basin (as shown in Figure 1). Due to great elevation variation intervals in the basin, the hydrothermal conditions display large differences in the form of vegetation and soil types, as well as vertical and horizontal gradient differences. From the lowest to highest altitudes, the vegetation types can be described as mountain desert, mountain grassland, mountain forest grassland, subalpine meadow, and mountain snow vegetation. The soil types include mountain sierozem, mountain chestnut soil, mountain gray cinnamonic soil, subalpine shrub meadow soil, and alpine frost desert soil. Among all of the soils, the mountain gray cinnamonic soil and the sub-alpine shrub meadow soil are the soils involved in forest growth, and are distributed in the regions with altitudes of 2400 to $3300 \mathrm{~m}$ and 3300 to $4000 \mathrm{~m}$, respectively. Among the edificatories, the Qinghai Picea crassifolia is distributed as patches or strips on the shaded and half-shaded slopes, at altitudes between 2400 and $3300 \mathrm{~m}$ in the test area, staggered with grassland on the sunny slopes.

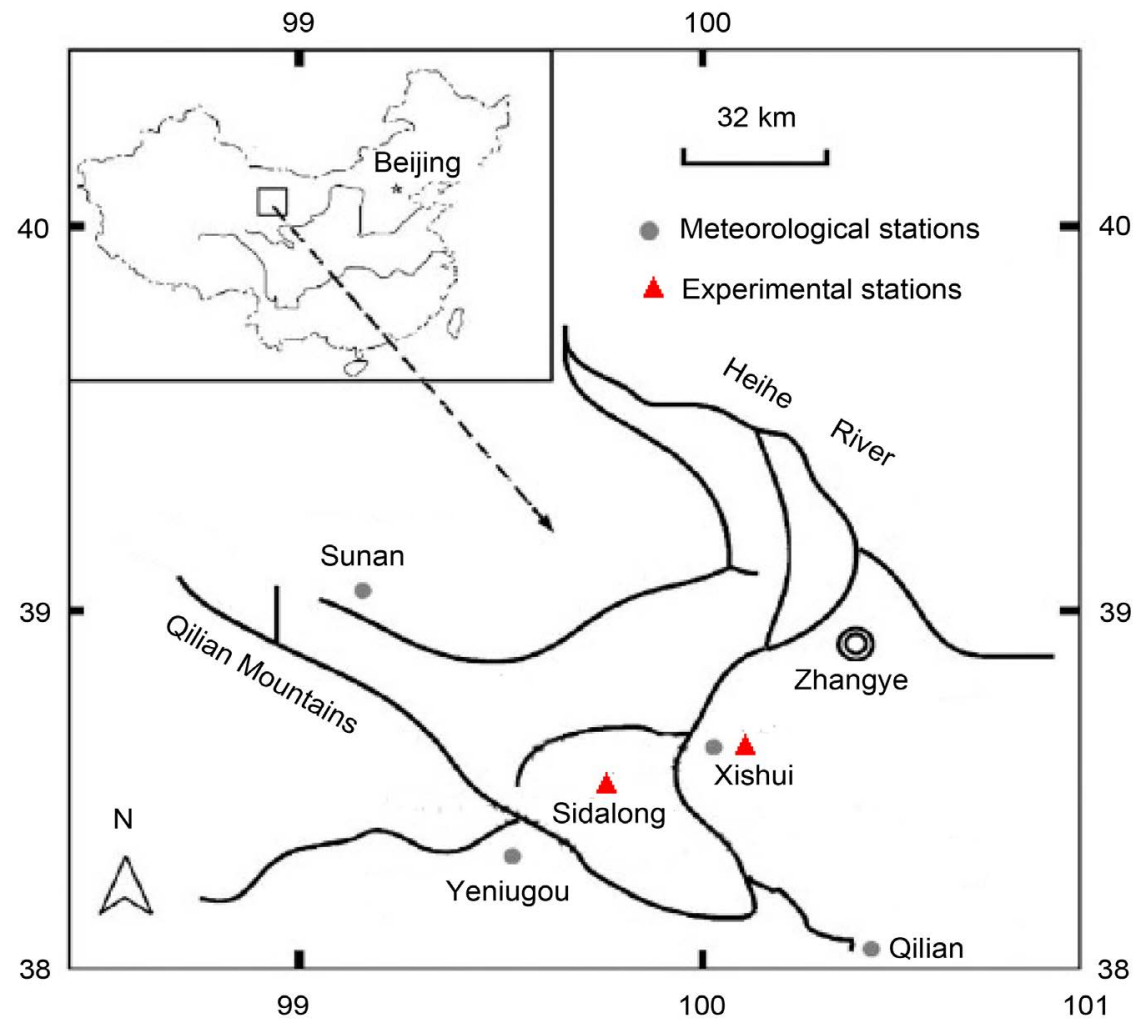

Figure 1. Position sketch map of the Dayekou basin of the Qilian Mountains. 
The Qilian Sibina przewal ski is distributed as small blocks on the sunny and half sunny slopes. The shrubs which are dominant species include: Potentilla fruticosa Linn., Caragana jubata (Pall.) Poir, Salix gilashanica C. Wang et PYFu, and so on. The herbaceous plants mainly consist of Polygonum viviparum Linn., Carex heterostachya Bge., Stipa capillata Linn., and so on. This basin is closed, with soil and vegetation typicality in spatial changes, and is an ideal experimental zone to study basin eco-hydrological processes, with soil freezing and thawing as one of the important ecological factors.

\section{Research Methods}

\subsection{Sample Plot Layout and Instrument Installation}

In this research study, in accordance with the different basin elevations, slope directions, slope gradients, and vegetation types, as well as their representatives, 15 sample plots were set up in October of 2013 (the sample plot situation is labeled by a sample plot number in Table 1). In each sample plot, a freezing meter was installed to monitor the phenomenon of soil freezing and thawing as detailed in the following table. Then, according to the thickness of the soil, the outer casings with lengths of $300 \mathrm{~cm}, 200 \mathrm{~cm}$ or $150 \mathrm{~cm}$, and diameters of $5 \mathrm{~cm}$ were set into the underground area. Meanwhile, a rubber freezing tube with a diameter of $1 \mathrm{~cm}$ equal to the outer casing was injected with water, and the gaps between the outer casing and soil were backfilled to prevent precipitation entering. The changes in the soil's freezing and thawing processes were determined according to the water freezing scale of the freezing meter.

Table 1. Sample number and its basic situation.

\begin{tabular}{|c|c|c|c|c|c|c|c|c|}
\hline Sample No. & Altitude/m & GPS-E & GPS-N & Sample/m & Forest type & Slope direction $/^{\circ}$ & Gradient $/^{\circ}$ & Crown density \\
\hline $\mathrm{T}_{1}$ & 2518 & $100^{\circ} 17^{\prime} 29.2^{\prime \prime}$ & $38^{\circ} 34^{\prime} 49.4^{\prime \prime}$ & $20 \times 20$ & Moss spruce forest & 9 & 36 & 0.69 \\
\hline $\mathrm{T}_{2}$ & 2579 & $100^{\circ} 17^{\prime} 18^{\prime \prime}$ & $38^{\circ} 34^{\prime} 1^{\prime \prime}$ & $20 \times 20$ & Shrub grassland & 28 & 6 & 0.75 \\
\hline $\mathrm{T}_{3}$ & 2600 & $100^{\circ} 18^{\prime} 2.7^{\prime \prime}$ & $38^{\circ} 32^{\prime} 40.8^{\prime \prime}$ & $20 \times 20$ & Grass shrub forest & 26 & 34 & 0.60 \\
\hline $\mathrm{T}_{4}$ & 2610 & $100^{\circ} 17^{\prime} 23.6^{\prime \prime}$ & $38^{\circ} 34^{\prime} 3.2^{\prime \prime}$ & $20 \times 20$ & Moss spruce forest & 61 & 32 & 0.70 \\
\hline $\mathrm{T}_{5}$ & 2701 & $100^{\circ} 17^{\prime} 10^{\prime \prime}$ & $38^{\circ} 33^{\prime} 11^{\prime \prime}$ & $20 \times 20$ & Shrub grassland & 48 & 10 & 0.50 \\
\hline $\mathrm{T}_{6}$ & 2720 & $100^{\circ} 17^{\prime} 6^{\prime \prime}$ & $38^{\circ} 33^{\prime} 18^{\prime \prime}$ & $20 \times 20$ & Moss spruce forest & 47 & 30 & 0.70 \\
\hline $\mathrm{T}_{7}$ & 2840 & $100^{\circ} 17^{\prime} 37^{\prime \prime}$ & $38^{\circ} 33^{\prime} 5^{\prime \prime}$ & $20 \times 20$ & Grass spruce forest & 56 & 30 & 0.82 \\
\hline $\mathrm{T}_{8}$ & 2900 & $100^{\circ} 18^{\prime} 2.7^{\prime \prime}$ & $38^{\circ} 32^{\prime} 40.8^{\prime \prime}$ & $20 \times 20$ & Grass shrub forest & 61 & 12 & 0.50 \\
\hline $\mathrm{T}_{9}$ & 2923 & $100^{\circ} 18^{\prime} 6^{\prime \prime}$ & $38^{\circ} 32^{\prime} 42^{\prime \prime}$ & $20 \times 20$ & Moss spruce forest & 16 & 32 & 0.80 \\
\hline $\mathrm{T}_{10}$ & 2946 & $100^{\circ} 17^{\prime} 59^{\prime \prime}$ & $38^{\circ} 32^{\prime} 47^{\prime \prime}$ & $20 \times 20$ & Sunny slope grassland & 220 & 33 & 0.36 \\
\hline $\mathrm{T}_{11}$ & 3028 & $100^{\circ} 17^{\prime} 59^{\prime \prime}$ & $38^{\circ} 32^{\prime} 39^{\prime \prime}$ & $20 \times 20$ & Moss spruce forest & 10 & 25 & 0.70 \\
\hline $\mathrm{T}_{12}$ & 3100 & $100^{\circ} 18^{\prime} 13^{\prime \prime}$ & $38^{\circ} 32^{\prime} 31^{\prime \prime}$ & $20 \times 20$ & Shrub spruce forest & 22 & 27 & 0.70 \\
\hline $\mathrm{T}_{13}$ & 3195 & $100^{\circ} 18^{\prime} 6^{\prime \prime}$ & $38^{\circ} 32^{\prime} 25^{\prime \prime}$ & $20 \times 20$ & Shrub spruce forest & 69 & 35 & 0.66 \\
\hline $\mathrm{T}_{14}$ & 3300 & $100^{\circ} 18^{\prime} 16^{\prime \prime}$ & $38^{\circ} 32^{\prime} 20^{\prime \prime}$ & $20 \times 20$ & Shrub spruce forest & 39 & 34 & 0.70 \\
\hline $\mathrm{T}_{15}$ & 3300 & $100^{\circ} 18^{\prime} 14.5^{\prime \prime}$ & $38^{\circ} 32^{\prime} 7.8^{\prime \prime}$ & $20 \times 20$ & Subalpine shrub forest & 41 & 33 & 0.80 \\
\hline
\end{tabular}




\subsection{Data Acquisition and Processing}

1) Every five days, observations were basically carried out from an altitude between 2500 and $3300 \mathrm{~m}$ throughout the year.

2) The eigenvalue parameter algorithm is shown as below:

$$
C v=\frac{\sigma}{\mu}, \mu=\frac{1}{N} \sum_{i=1}^{N} x_{i}, \sigma=\sqrt{\frac{1}{N} \sum_{i=1}^{N}\left(x_{i}-\mu\right)^{2}}
$$

In the equation, $\mu, \sigma$, and $C v$ are the average, standard deviation and variation coefficient of the freezing-thawing of soil, respectively; $x_{i}$ is the measured values of the soil's freezing-thawing process; and $N$ is the statistical number.

A correlation analysis method was used for the correlation analysis and modeling parameter screening of the freezing days, thawing days, freezing rate and thawing rate with altitude, slope direction, slope gradient, and crown density. Then, a stepwise regression analysis method was adopted to determine the regression model of the soil's freezing-thawing and space factor, in order to establish a regression model for the $R$ fitting, $F$ variance, and $t$ regression coefficient tests.

\section{Results and Analyses}

\subsection{Soil Freezing-Thawing Variation Process}

\subsubsection{Spatial Variation Characteristics}

The soil's freezing-thawing process included two stages: soil' freezing, and soil thawing. Driven by the ground temperatures, these two processes occur alternately. In order to facilitate the research, the soil's thickness is shown as an increase over a period of time overall, and is usually referred to as soil freezing. It may be referred to as soil thawing. As can be seen in Table 1 and Table 2, within the soil scope with a depth of $150 \mathrm{~cm}$, the soil's freezing-thawing rate displayed different response degrees to the changes in the different space factors, such as the altitude, slope direction, and slope gradient, as well as the vegetation crown density. As shown in Figure 2, the soil's freezing rate presented a trend of fluctuation increases with the rising altitude, while the soil's thawing rate showed an opposite trend. Then, by utilizing the same method, it was determined that the variation coefficient of the soil's freezing-thawing increased with the altitude, and displayed a trend of increased fluctuations. The ending time of the soil's freezing presented a trend of fluctuation prior to the rising altitude. Meanwhile, the ending time of the thawing displayed an opposite trend. Therefore, during the space change sorting of the soil's freezing-thawing rate, for the variation coefficient, starting time, and ending time (in the cases of the same value), the altitude was taken as a secondary discrimination factor for the evaluation. The soil's freezing rate was sequenced from smallest to largest as follows: the moss spruce forest with an altitude of $3028 \mathrm{~m}<$ shrub grassland with an altitude of $2579 \mathrm{~m}<$ sunny slope grassland with an altitude of $2946 \mathrm{~m}<$ shrub spruce forest 
Table 2. Spatial variation features of the rate of soil freezing and thawing in the Dayekou Basin of the Qilian Mountains.

\begin{tabular}{|c|c|c|c|c|c|c|c|c|c|c|}
\hline \multirow[b]{2}{*}{ Altitude/m } & \multicolumn{5}{|c|}{ Freezing rate $/ \mathrm{cm} \cdot \mathrm{d}^{-1}$} & \multicolumn{5}{|c|}{ Thawing rate $/ \mathrm{cm} \cdot \mathrm{d}^{-1}$} \\
\hline & Average & $\begin{array}{l}\text { Standard } \\
\text { deviation }\end{array}$ & $\begin{array}{l}\text { Coefficient of } \\
\text { variation }\end{array}$ & Lower limit & Upper limit & Average & $\begin{array}{l}\text { Standard } \\
\text { deviation }\end{array}$ & $\begin{array}{l}\text { Coefficient of } \\
\text { variation }\end{array}$ & Lower limit & Upper limit \\
\hline 2518 & 1.3 & 0.3 & 0.2 & 1.0 & 1.6 & 1.9 & 1.7 & 0.9 & 0.2 & 3.6 \\
\hline 2579 & 1.2 & 0.4 & 0.3 & 0.8 & 1.6 & 1.8 & 1.1 & 0.6 & 0.7 & 2.9 \\
\hline 2600 & 2.0 & 0.7 & 0.3 & 1.4 & 2.7 & 2.5 & 2.1 & 0.9 & 0.4 & 4.6 \\
\hline 2610 & 1.8 & 0.5 & 0.3 & 1.3 & 2.4 & 2.3 & 2.6 & 1.1 & 0.0 & 4.9 \\
\hline 2701 & 1.5 & 0.2 & 0.2 & 1.2 & 1.7 & 1.3 & 0.9 & 0.7 & 0.4 & 2.2 \\
\hline 2720 & 1.3 & 0.4 & 0.4 & 0.8 & 1.7 & 1.3 & 1.4 & 1.1 & 0.0 & 2.7 \\
\hline 2840 & 3.1 & 1.4 & 0.5 & 1.7 & 4.6 & 0.9 & 1.7 & 1.8 & 0.0 & 2.6 \\
\hline 2900 & 1.7 & 0.6 & 0.3 & 1.1 & 2.2 & 1.2 & 0.9 & 0.8 & 0.3 & 2.1 \\
\hline 2923 & 1.7 & 0.6 & 0.4 & 1.1 & 2.3 & 1.0 & 1.3 & 1.4 & 0.0 & 2.3 \\
\hline 2946 & 1.2 & 1.0 & 0.8 & 0.2 & 2.2 & 4.0 & 2.9 & 0.7 & 1.1 & 6.9 \\
\hline 3028 & 1.0 & 0.5 & 0.5 & 0.5 & 1.6 & 0.8 & 1.3 & 1.7 & 0.0 & 2.1 \\
\hline 3100 & 1.2 & 0.4 & 0.4 & 0.8 & 1.6 & 0.8 & 1.0 & 1.3 & 0.0 & 1.8 \\
\hline 3195 & 2.1 & 0.6 & 0.3 & 1.5 & 2.7 & 0.9 & 2.0 & 2.1 & 0.0 & 2.9 \\
\hline 3300 & 2.2 & 2.2 & 1.0 & 0.0 & 4.4 & 0.8 & 1.1 & 1.3 & 0.0 & 1.9 \\
\hline 3300 & 4.6 & 2.4 & 0.5 & 2.2 & 6.9 & 1.2 & 1.1 & 0.9 & 0.1 & 2.3 \\
\hline Mean & 1.9 & 0.8 & 0.4 & 1.0 & 2.7 & 1.5 & 1.5 & 1.2 & 0.2 & 3.1 \\
\hline
\end{tabular}

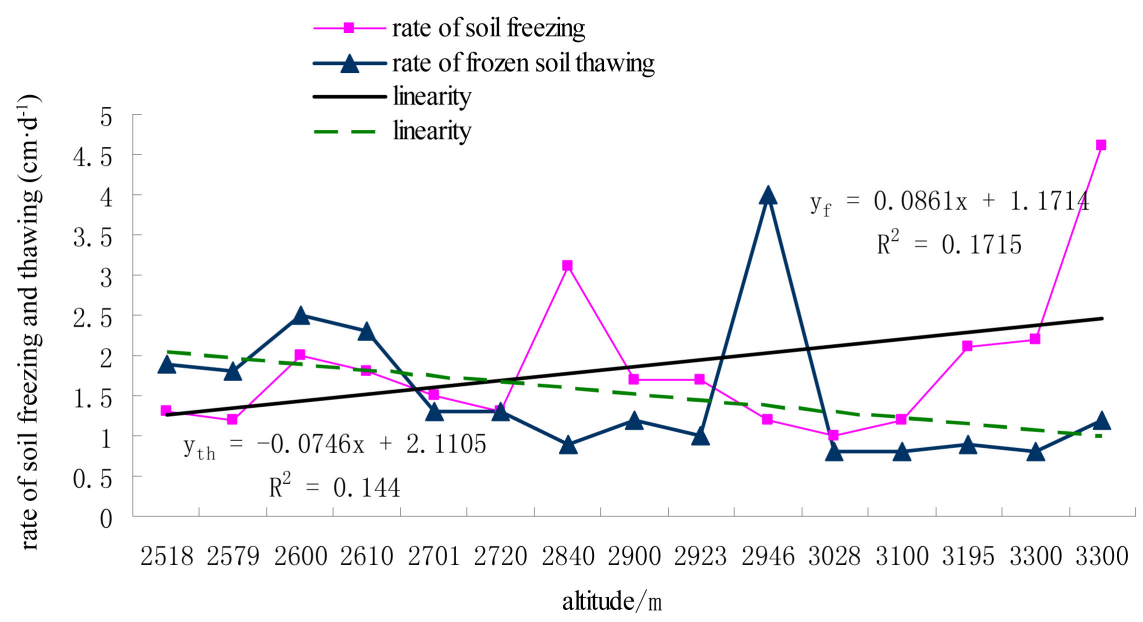

Figure 2. Spatial variation features of the rate of soil freezing and thawing with altitude in the Dayekou Basin of the Qilian Mountains.

with an altitude of $3100 \mathrm{~m}<$ moss spruce forest with an altitude of $2518 \mathrm{~m}<$ moss spruce forest with an altitude of $2720 \mathrm{~m}<$ shrub grassland with an altitude of $2701 \mathrm{~m}<$ grass shrub forest with an altitude of $2900 \mathrm{~m}<$ moss spruce forest with an altitude of $2923 \mathrm{~m}<$ moss spruce forest with an altitude of $2610 \mathrm{~m}<$ grass shrub forest with an altitude of $2600 \mathrm{~m}<$ shrub spruce forest with an altitude of $3195 \mathrm{~m}<$ shrub spruce forest with an altitude of $3300 \mathrm{~m}<$ grass spruce forest with an altitude of $2840 \mathrm{~m}<$ subalpine shrub forest with an altitude of 
$3300 \mathrm{~m}$, averaged at $1.9 \mathrm{~cm} \cdot \mathrm{d}^{-1}$. The soil's thawing rate was sequenced from smallest to largest as follows: the shrub spruce forest with an altitude of $3300 \mathrm{~m}<$ shrub spruce forest with an altitude of $3100 \mathrm{~m}<$ moss spruce forest with an altitude of $3028 \mathrm{~m}<$ shrub spruce forest with an altitude of $3195 \mathrm{~m}<$ grass spruce forest with an altitude of $2840 \mathrm{~m}<$ moss spruce forest with an altitude of 2923 $\mathrm{m}<$ subalpine shrub forest with an altitude of $3300 \mathrm{~m}<$ grass shrub forest with an altitude of $2900 \mathrm{~m}<$ moss spruce forest with an altitude of $2720 \mathrm{~m}<$ shrub grassland with an altitude of $2701 \mathrm{~m}<$ shrub grassland with an altitude of 2579 $\mathrm{m}<$ moss spruce forest with an altitude of $2518 \mathrm{~m}<$ moss spruce forest with an altitude of $2610 \mathrm{~m}<$ grass shrub forest with an altitude of $2600 \mathrm{~m}<$ sunny slope grassland with an altitude of $2946 \mathrm{~m}$, averaged at $1.5 \mathrm{~cm} \cdot \mathrm{d}^{-1}$.

The variation coefficient was an indicator to study the variation degree of the freezing-thawing process of soil (Table 2). Within the soil scope with a depth of $150 \mathrm{~cm}$, the soil freezing variation was sequenced from smallest to largest as follows: the moss spruce forest with an altitude of $2518 \mathrm{~m}<$ shrub grassland with an altitude of $2701 \mathrm{~m}<$ shrub grassland with an altitude of $2579 \mathrm{~m}<$ grass shrub forest with an altitude of $2600 \mathrm{~m}<$ moss spruce forest with an altitude of 2610 $\mathrm{m}<$ grass shrub forest with an altitude of $2900 \mathrm{~m}<$ scrub spruce forest with an altitude of $3195 \mathrm{~m}<$ moss spruce forest with an altitude of $2720 \mathrm{~m}<$ moss spruce forest with an altitude of $2923 \mathrm{~m}<$ shrub spruce forest with an altitude of $3100 \mathrm{~m}<$ grass spruce forest with an altitude of $2840 \mathrm{~m}<$ moss spruce forest with an altitude of $3028 \mathrm{~m}<$ subalpine shrub forest with an altitude of $3300 \mathrm{~m}<$ sunny slope grassland with an altitude of $2946 \mathrm{~m}<$ shrub spruce forest with an altitude of $3300 \mathrm{~m}$, averaged at 0.4 . The soil's thawing change was sequenced from smallest to largest as follows: the shrub grassland with an altitude of 2579 $\mathrm{m}<$ shrub grassland with an altitude of $2701 \mathrm{~m}<$ sunny slope grassland with an altitude of $2946 \mathrm{~m}<$ grass shrub forest with an altitude of $2900 \mathrm{~m}<$ moss spruce forest with an altitude of $2518 \mathrm{~m}<$ grass shrub forest with an altitude of 2600 $\mathrm{m}<$ subalpine forest with an altitude of $3300 \mathrm{~m}<$ moss spruce forest with an altitude of $3300 \mathrm{~m}<$ moss spruce forest with an altitude of $2720 \mathrm{~m}<$ shrub spruce forest with an altitude of $3100 \mathrm{~m}<$ shrub spruce forest with an altitude of 3300 $\mathrm{m}<$ moss spruce forest with an altitude of $2923 \mathrm{~m}<$ moss spruce forest with an altitude of $3028 \mathrm{~m}<$ grass spruce forest with an altitude of $2840 \mathrm{~m}<$ shrub spruce forest with an altitude of $3195 \mathrm{~m}$, averaged at 1.2.

\subsubsection{Variation Characteristics of the Starting and Ending Time}

The changes in the different space factors, such as altitude, slope direction, and slope gradient, as well as the vegetation crown density, were found to have different effects on the starting and ending time of the soil's freezing-thawing process. As can be seen in Figure 3 and Figure 4, the starting time of the soil's freezing-thawing had only a minimal difference. However, the freezing time of the soil with a depth of $150 \mathrm{~cm}$ was found to be quite different (shortened to soil freezing time in this study). The soil freezing began on approximately October $20^{\text {th }}$, and the soil freezing rate gradually decreased over time. The freezing time 


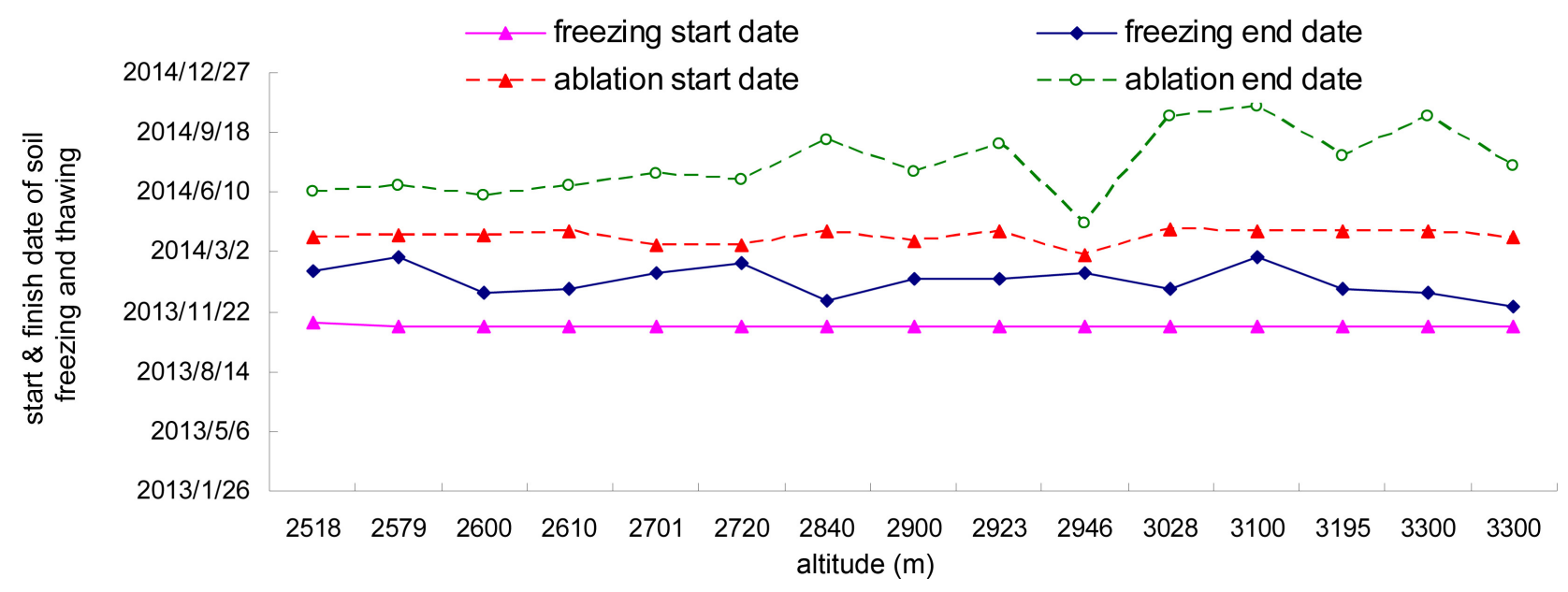

Figure 3. Spatial variation features of the star in end time of the soil freezing and thawing in the Dayekou Basin of the Qilian Mountains.

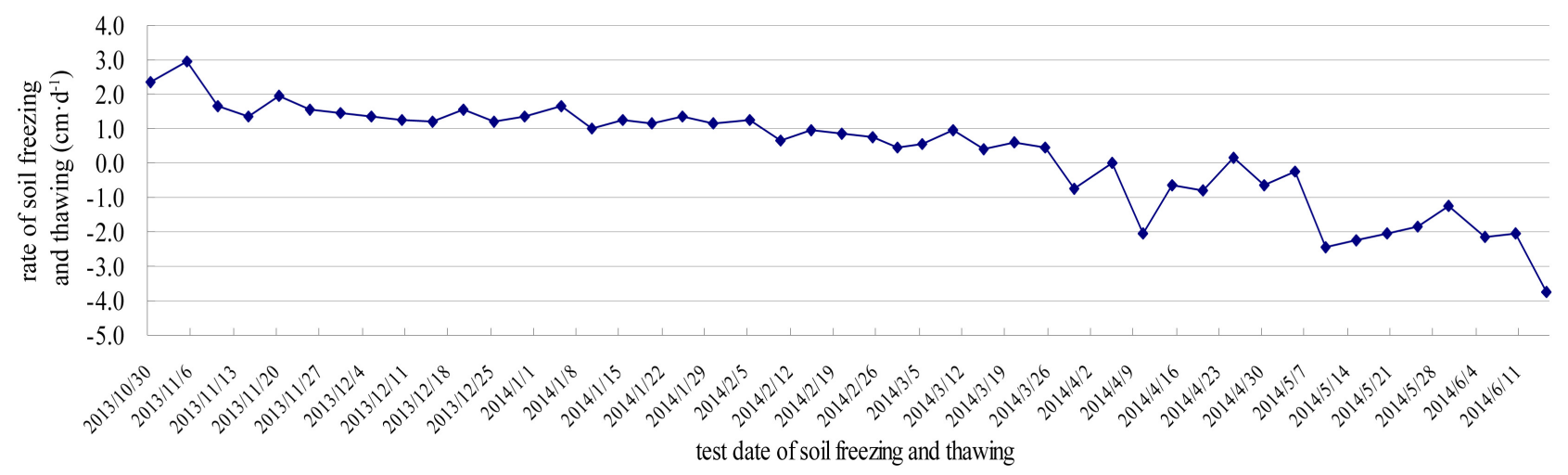

Figure 4. Time representations of the soil's freezing and thawing process in the Dayekou Basin of the Qilian Mountains. Note: Figure 4 was prepared using the data of the typical $\mathrm{T}_{2}, \mathrm{~T}_{5}$ and $\mathrm{T}_{6}$ sample plots.

of the soil with depths of $150 \mathrm{~cm}$ was sequenced from early to late as follows: the subalpine shrub forest with an altitude of $3300 \mathrm{~m}<$ grass spruce forest with an altitude of $2840 \mathrm{~m}<$ grass shrub forest with an altitude of $2600 \mathrm{~m}<$ scrub spruce forest with an altitude of $3300 \mathrm{~m}<$ moss spruce forest with an altitude of $2610 \mathrm{~m}<$ moss spruce forest with an altitude of $3028 \mathrm{~m}<$ shrub spruce forest with an altitude of $3195 \mathrm{~m}<$ grass shrub forest with an altitude of $2900 \mathrm{~m}<$ moss spruce forest with an altitude of $2923 \mathrm{~m}<$ shrub grassland with an altitude of $2701 \mathrm{~m}<$ sunny slope grassland with an altitude of $2946 \mathrm{~m}<$ moss spruce forest with an altitude of $2518 \mathrm{~m}<$ moss spruce forest with an altitude of $2720 \mathrm{~m}<$ shrub grassland with an altitude of $2579 \mathrm{~m}<$ shrub spruce forest with an altitude of $3100 \mathrm{~m}$, averaged on January $12^{\text {th }}$. The data of soil's thawing of the $150 \mathrm{~cm}$ deep soil also displayed small differences, and was averaged on March $27^{\text {th }}$. The soil's thawing rate was observed to increase gradually over time, and is marked by a negative value in Figure 4. The ending time of soil's thawing was sequenced from early to late as follows: the sunny slope grassland with an altitude of 2946 $\mathrm{m}<$ grass shrub forest with an altitude of $2600 \mathrm{~m}<$ moss spruce forest with an 
altitude of $2518 \mathrm{~m}<$ shrub grassland with an altitude of $2579 \mathrm{~m}<$ moss spruce forest with an altitude of $2610 \mathrm{~m}<$ moss spruce forest with an altitude of $2720 \mathrm{~m}<$ shrub grassland with an altitude of $2701 \mathrm{~m}<$ grass shrub forest with an altitude of $2900 \mathrm{~m}<$ subalpine shrub forest with an altitude of $3300<$ shrub spruce forest with an altitude of $3195 \mathrm{~m}<$ moss spruce forest with an altitude of $2923 \mathrm{~m}<$ grass spruce forest with an altitude of $2840 \mathrm{~m}<$ moss spruce forest with an altitude of $3028 \mathrm{~m}<$ shrub spruce forest with an altitude of $3300 \mathrm{~m}<$ shrub spruce forest with an altitude of $3100 \mathrm{~m}$, averaged at July $27^{\text {th }}$.

\subsubsection{Duration Variation Characteristics}

Within the soil scope with a depth of $150 \mathrm{~cm}$, the soil's freezing-thawing duration displayed different responses to the changes in space factors, such as altitude, slope direction, and slope gradient, as well as the vegetation crown density. As shown in Figure 5, the total durations of the soil freezing, soil's thawing and freezing-thawing were averaged 77, 121 and 199 days, respectively.

\subsection{Correlation Analysis between the Freezing-Thawing Process of the Soil and the Space Factors}

The sample plot observations of the different space factors in the basin were selected for the correlation analysis. In the case of $a=0.1(P<0.1)$, the Chad threshold $F_{0.1}(1,14)$ was 3.102 , and the correlation coefficient threshold $r_{0.1}=\sqrt{F_{0.1}(1,15) /\left(F_{0.1}(1,15)+15\right)}$ was substituted to obtain $r_{0.1}$ at 0.441 . If the correlation coefficient was found to be greater than the critical value, it indicated a significant correlation. Meanwhile, if it was less than the critical value, this indicated insignificant correlations (the values with " $\star$ ” in Table 3 indicate significant correlations, while the values with no “*” indicate insignificant correlations). As shown in Table 3, the freezing days displayed significant correlations with the slope gradient, moderate correlations with the altitude, and rather weak correlations with the other factors. The thawing days displayed significantly positive correlations to the altitude and crown density, while negative correlations

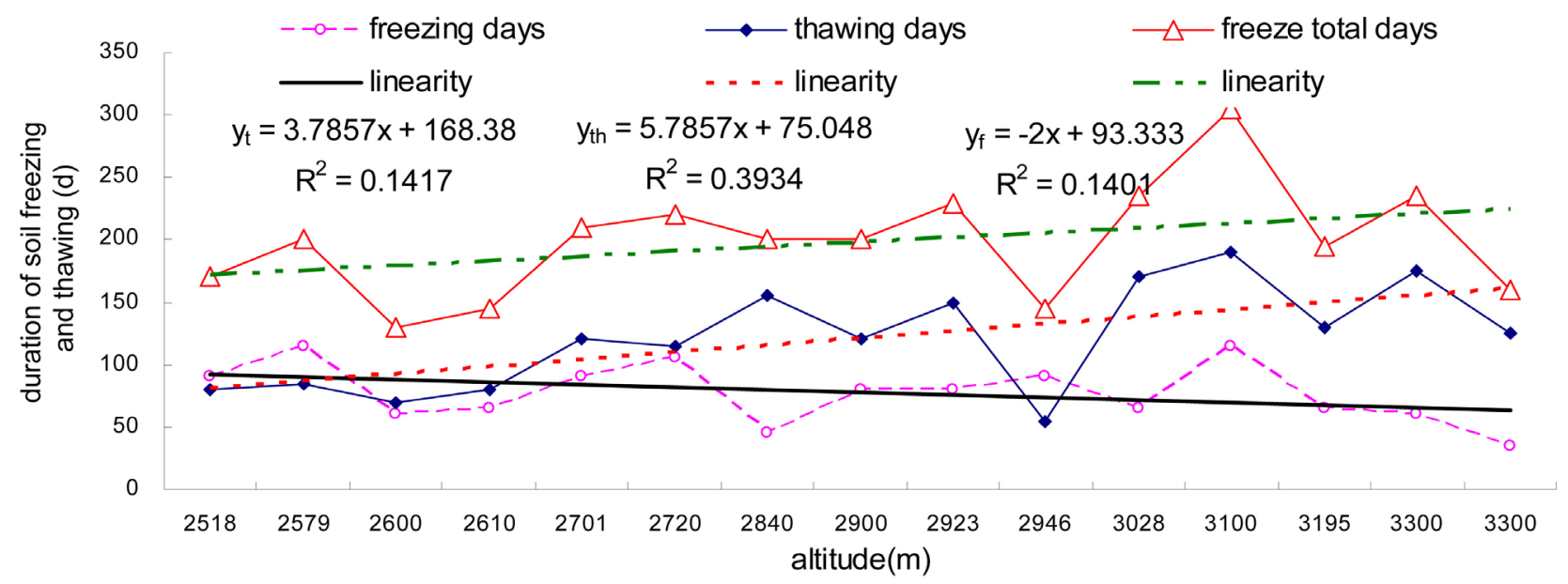

Figure 5. Durations of the soil's freezing and thawing process in the Dayekou Basin of the Qilian Mountains. 
Table 3. Correlation coefficient of the soil's freezing-thawing process and the spatial factors in the Dayekou Basin of the Qilian Mountains.

\begin{tabular}{|c|c|c|c|c|c|c|c|c|}
\hline & Altitude /m & $\begin{array}{c}\text { Slope } \\
\text { direction/ }\end{array}$ & Gradient ${ }^{\circ}$ & $\begin{array}{l}\text { Crown } \\
\text { density }\end{array}$ & $\begin{array}{l}\text { Freeze } \\
\text { days/d }\end{array}$ & $\begin{array}{c}\text { Thawing } \\
\text { days/d }\end{array}$ & $\begin{array}{c}\text { Freezing } \\
\text { rate } / \mathrm{cm} \cdot \mathrm{d}^{-1}\end{array}$ & $\begin{array}{l}\text { Freezing } \\
\mathrm{rate} / \mathrm{cm} \cdot \mathrm{d}^{-1}\end{array}$ \\
\hline Altitude/m & 1.000 & & & & & & & \\
\hline Slope direction $/^{\circ}$ & 0.114 & 1.000 & & & & & & \\
\hline Gradient $/^{\circ}$ & 0.283 & 0.116 & 1.000 & & & & & \\
\hline Crown density & 0.122 & $-0.688^{*}$ & 0.218 & 1.000 & & & & \\
\hline Freeze days/d & -0.395 & 0.029 & $-0.455^{*}$ & -0.264 & 1.000 & & & \\
\hline Thawing days/d & $0.643^{*}$ & $-0.447^{\star}$ & 0.011 & $0.460^{*}$ & -0.127 & 1.000 & & \\
\hline Freezing rate $/ \mathrm{cm} \cdot \mathrm{d}^{-1}$ & $0.448^{*}$ & -0.055 & 0.296 & 0.414 & $-0.779^{\star}$ & 0.132 & 1.000 & \\
\hline Freezing rate $/ \mathrm{cm} \cdot \mathrm{d}^{-1}$ & -0.424 & $0.711^{*}$ & 0.134 & $-0.613^{*}$ & 0.151 & $-0.859^{\star}$ & -0.223 & 1.000 \\
\hline
\end{tabular}

Note: The values with * indicate significant correlations.

to the slope direction. The freezing rate had a significantly positive correlation with the altitude, a moderate correlation with the crown density, and rather weak correlations with the other factors. The thawing rate displayed a significantly positive correlation with the slope direction, a significantly negative correlation with the crown density, a moderate correlation with the altitude, and rather weak correlations with the other factors. Therefore, the freezing days with altitude and slope gradient; the thawing days with altitude, slope direction, and crown density; the freezing rate with altitude and crown density; and the thawing rate with altitude, slope direction, and crown density were preliminarily selected for this study's regression analysis.

\subsection{Fitting and Variance Analysis of the Freezing-Thawing Process of the Soil and the Space Factors}

Table 4 shows the $F$ test values, and the significant level of regression fitting and variance analysis. Generally speaking, in accordance with the complex phase relation interpretation standard, when the multiple correlation coefficient $|R|>$ 0.95 , significant correlations are indicated; $0.95 \leq|R| \geq 0.8$ indicates high correlations; $0.5 \leq|R|<0.8$ indicates moderate correlations; $0.3 \leq|R|<0.5$ indicates low correlations; and $|R|<0.3$ indicates rather weak correlations, which are considered as non-correlations [15]. Therefore, the fitting of the freezing days with altitude and slope gradient, as well as the freezing rate with altitude and crown density, belonged to moderate correlations, and the fitting of the thawing days with altitude, slope direction, and canopy density, as well as the thawing rate with altitude, slope direction, and crown density, belonged to high correlations. The established model passed the $R$ fitting test with ideal fitting results. The multiple determination coefficients showed that the independent variable could explain the weight of the dependent variable. It can be seen from Table 5 that the altitude, slope direction, and crown density could be used to predict $68.8 \%$ of the thawing duration variances. The adjusted multiple determination coefficients confirmed that the independent variables were able to explain the weight 
Table 4. Matching coefficients of the soil's freezing-thawing process and the spatial factors in the Dayekou Basin of the Qilian Mountains.

\begin{tabular}{|c|c|c|c|c|c|c|c|}
\hline $\begin{array}{l}\text { Dependent } \\
\text { variables }\end{array}$ & Independent variables & $R$ & $R^{2}$ & $\overline{R^{2}}$ & Standard error & $F$ test value & Significance level \\
\hline Freeze days & Altitude, gradient & 0.533 & 0.284 & 0.165 & 21.840 & 2.379 & 0.135 \\
\hline Thawing days & $\begin{array}{l}\text { Altitude, slope direction, } \\
\text { crown density }\end{array}$ & 0.830 & 0.688 & 0.603 & 25.981 & 8.098 & 0.004 \\
\hline Freezing rate & Altitude, crown density & 0.575 & 0.331 & 0.220 & 0.821 & 2.971 & 0.090 \\
\hline Thawing rate & $\begin{array}{l}\text { Altitude, slope direction, } \\
\text { crown density }\end{array}$ & 0.875 & 0.766 & 0.702 & 0.480 & 11.991 & 0.001 \\
\hline
\end{tabular}

Table 5. Partial regression coefficients of the duration of the soil's freezing-thawing and spatial factors in the Dayekou Basin of the Qilian Mountains.

\begin{tabular}{ccccccc}
\hline & Coefficients & Standard error & T Stat & $P$-value & Lower limit 95.0\% & Upper limit 95.0\% \\
\hline Constant & -179.923 & 85.148 & -2.113 & 0.058 & -367.332 & 7.485 \\
Altitude & 0.110 & 0.028 & 3.961 & 0.002 & 0.049 & 0.171 \\
Slope direction & -0.416 & 0.196 & -2.120 & 0.058 & -0.848 & 0.016 \\
Crown density & 7.225 & 78.399 & 0.092 & 0.928 & -165.329 & 179.779 \\
\hline
\end{tabular}

of the dependent variables' variations, and that the altitude, slope direction, and crown density could be used to explain $60.3 \%$ of the thawing duration changes. The remainder could be explained by other factors, such as the micro topography changes of the land surface. The standard error indicated that the average error was between the predicted and measured values. The smaller the value was, the more ideal the fitting degree was. The $F$ value shown in Table 4 is the test value of the variance analysis as the ratio of regression mean square error and residual mean square error. Therefore, if the regression mean square error is larger, and residual mean square error is smaller, the results should be expected to be more ideal. The greater the $F$ value was, the more ideal the predicted results of the model were. It can be seen from Table 4 that the level of $a=0.05$ ( $P$ $<0.05)$ could be used for another screening. The fitting of the thawing days with altitude, slope direction, and crown density, as well as the thawing rate with altitude, slope direction, and crown density, displayed significance levels of $P<$ 0.05 , which finally determined that the thawing days and thawing rate model passed the $F$ test of variance. Therefore, the regression models of the thawing days with altitude, slope direction, and crown density, as well as the thawing rate with altitude, slope direction, and crown density, were determined for the partial regression coefficient analysis of this study.

\subsection{Partial Regression Coefficient Analysis of the Soil's Freezing-Thawing Process and the Space Factors}

In Table 5 and Table 6 , the $P$-value indicates the significance degree of the partial regression coefficient. The smaller the $P$-value is, the more significant the variation in the partial regression coefficient is. In Table 5 and Table 6, the 
Table 6. Partial regression coefficients of the duration of the soil's freezing-thawing and spatial factors in the Dayekou Basin of the Qilian Mountains.

\begin{tabular}{ccccccc}
\hline & Coefficients & Standard error & T Stat & $P$-value & Lower limit 95.0\% & Upper limit 95.0\% \\
\hline Constant & 5.946 & 1.574 & 3.777 & 0.003 & 2.481 & 9.410 \\
Altitude & -0.002 & 0.001 & -3.293 & 0.007 & -0.003 & -0.001 \\
Slope direction & 0.013 & 0.004 & 3.534 & 0.005 & 0.005 & 0.021 \\
Crown density & -0.298 & 1.449 & -0.206 & 0.841 & -3.488 & 2.892 \\
\hline
\end{tabular}

$P$-values of the crown density are all greater than 0.5 , which did not pass the $t$ test, thus these were eliminated. Then, a stepwise regression analysis method was used to screen the thawing days with altitude and slope direction, as well as the thawing rate with altitude and slope direction, by again using the $t$ test method (as in Table 5 and Table 6). The results showed that the $P$-values of the thawing-days model with altitude and slope direction were all less than 0.05 , and those of the thawing rate model with altitude and slope direction were all less than 0.005 . The regression models all passed the $t$ test with a confidence level of $99 \%$ or more.

In this study, the results of the above $R$ fitting test were combined with those of the $F$ variance and $t$ regression coefficient tests, and the regression models of the thawing duration and thawing rate could be obtained as follows:

$$
\begin{gathered}
T_{a}=0.111 a-0.429 e-176.527\left(R^{2}=0.830, P<0.001\right) \\
V_{a}=0.013 e-0.002 a+5.805\left(R^{2}=0.875, P<0.001\right)
\end{gathered}
$$

In the equation, $T_{a}$ and $V_{a}$ represent the soil's thawing duration (d) and thawing rate $\left(\mathrm{cm} \cdot \mathrm{d}^{-1}\right)$ with the different altitudes and slope directions, respectively; $a$ and $e$ are the basin's altitude $(\mathrm{m})$ and slope direction $\left({ }^{\circ}\right)$, respectively.

\section{Discussions and Conclusions}

\subsection{Discussions}

It was determined in this study that the seasonal frozen soils were widely distributed in the Qilian Mountains, and were mainly comprehensively affected by topography, altitude, slope direction, slope gradient, slope position, soil type, composition, and structure, as well as other factors, which caused great differences in the freezing-thawing process within the basin. In particular, the spatial variation characteristics of the soil's freezing and thawing displayed seasonal variation laws over time. However, under the influence of different space factors, the presented characteristics were found to not be identical. The soil's freezing and thawing process is complex. The soil's freezing process and the soil's thawing process display different response sensitivities to space factor changes. It was preliminarily determined in this study that the altitude and slope direction had the most significant effects on the soil's thawing process. The soil layer in the alpine glacier permafrost zone and the seasonal frozen soil layer in the mid-low mountains were determined to be the links to connect the "solid reservoir", 
"green reservoir", and river water systems. Due to the unique hydrothermal properties, a special underlying surface is formed which is beneficial to the river runoff, and thereby plays a role in water conservation and river runoff regulation. In this study, the fitting relationship between the soil's freezing-thawing process and the topographic space factors was considered as a rough estimation relationship, with more focus on a single factor, and less focus on comprehensive factors. In the future, scientific research in this area should pay closer attention to the spatial inter-annual and seasonal changes in the soil freezing and thawing process, as well as the response characteristics to latitude and longitude. Therefore, through further research, the exploration of the spatial response relationship between global climate warming and soil's freezing-thawing may potentially provide reference data for human responses to worsening ecological environment problems.

\subsection{Conclusions}

1) The soil freezing rate showed a trend of fluctuation increases with rising altitude, while the soil's thawing rate displayed the opposite trend. The soil's freezing-thawing variation degree presented a trend of fluctuation increase with rising altitude. The ending time of the soil freezing showed a trend of fluctuation in advance with the rising altitude, while the trend of the thawing was found to be the opposite.

2) In the spatial sequence, the soil's freezing rate averaged at $1.9 \mathrm{~cm} \cdot \mathrm{d}^{-1}$. The soil's thawing rate averaged at $1.5 \mathrm{~cm} \cdot \mathrm{d}^{-1}$. The soil freezing variation degree averaged at 0.4. Finally, the soil's thawing variation degree averaged at 1.2.

3) The soil freezing began on approximately October $20^{\text {th }}$, and the soil freezing rate became gradually reduced. The frozen soil thickness reached $150 \mathrm{~cm}$ averaged on January $12^{\text {th }}$. The soil's thawing to a soil depth of $150 \mathrm{~cm}$ had smaller time differences, averaged on March $27^{\text {th }}$. Then, the soil's thawing rate gradually increased. The soil's thawing ended and averaged on July $27^{\text {th }}$. The average durations of the soil's freezing, soil's thawing, and total soil's freezing-thawing were 77, 121, and 199 days, respectively.

4) The established thawing duration and thawing rate regression models all passed the $R$ fitting, $F$ variance, and $t$ regression coefficient tests.

\section{Conflicts of Interest}

The authors declare no conflicts of interest regarding the publication of this paper.

\section{References}

[1] Niu, Y., Liu, X.D., Jing, W.M., et al. (2014) Characteristics of Temperature, Soil Freezing and Thawing, and River Flow in the Pailugou Watershed of the Qilian Mountains. Scientia Silvae Sinicae, 50, 27-31.

[2] Zhang, W., Wang, G.X., Zhou, J., et al. (2012) The Soil Hydrothermal Process Simulation Based on a Coup Model in the Permafrost Regions of the Qinghai-Tibet 
Plateau. The Journal of Glaciology and Geocryology, 34, 1099-1109.

[3] Wang, C.H., Jin, S.L. and Shi, H.X. (2014) Area Changes of the Frozen Ground in China in the Next 50 Years. Journal of Glaciology and Geocryology, 36, 1692-1696.

[4] Li, X. and Cheng, G.D. (1999) A Gis-Aided Response Model of the High-Altitude Permafrost to Global Changes. Science in China Series D: Earth Sciences, 42, 72-79. https://doi.org/10.1007/BF02878500

[5] Nan, Z.T., Li, S.X. and Cheng, G.D. (2005) Prediction of the Permafrost Distribution on the Qinghai-Tibet Plateau in the Next 50 and 100 Years. Science in China Series D: Earth Sciences, 48, 794-804.

[6] Nelson, F.E., Anisimov, O.A. and Shilomanov, N.I. (2002) The Climate Changes and Hazard Zonation in the Circum-Arctic Permafrost Regions. Nature Hazard, 26, 203-225. https://doi.org/10.1023/A:1015612918401

[7] Wang, Z.L., Fu, Q., Jiang, Q.X., et al. (2010) Spatial Variability of the Soil Moisture Profile in the Seasonal Frozen Soil Regions in Different Stages. Scientia Geographica Sinica, 30, 772-776.

[8] Wang, S.J. and Chen, J.B. (2008) Nonlinear Analysis for the Dimensional Effects of the Temperature Field of the Highway Embankments in Permafrost Regions on the Qinghai-Tibet Plateau. Chinese Journal of Geotechnical, 30, 1544-1549.

[9] Wang, Q.F., Zhang, T.J., Wu, J.C., et al. (2013) Investigation on Permafrost Distribution over the Upper Reaches of the Heihe River in the Qilian Mountains. The Journal of Glaciology and Geocryology, 35, 19-29.

[10] Peng, X.Q., Zhang, T.J., Pan, X.D., et al. (2013) Spatial and Temporal Variations of Seasonally Frozen Ground over the Heihe River Basin of Qilian Mountain in Western China. Advance in Earth Sciences, 28, 497-508.

[11] Zhang, W.J., Cheng, W.M., Li, B.L., et al. (2014) Simulation of the Permafrost Distribution on Qilian Mountains over Past 40 Years under the Influence of Climate Change. Geographical Research, 33, 1275-1284.

[12] Wang, J.Y., Kang, E.S. and Jin, B.W. (2001) Hydrological function of frozen soil in forest area in the upper reaches of the Heihe River. The Journal of North West Forestry University, 16, 30-34.

[13] Chang, X.X., Wang, J.Y., Jin, B.W., et al. (2001) The Freezing and Fusion Rule of Seasonal Frozen Soil and Its Hydrological Function in the Forest Areas of the Qilian Mountains. The Journal of North West Forestry University, S1, 26-29.

[14] Jin, M., Li, Y., Liu, X.D., et al. (2011) Interannual Variation Characteristics of Seasonal Frozen Soil in the Upper-Middle Reaches of the Heihe River in the Qilian Mountains. The Journal of Glaciology and Geocryology, 33, 1068-1073.

[15] Niu, Y., Li, B.X., Miao, Y.X., et al. (2015) The Relationship between the Desert Plant Growth and the Changes of Water in the Saline and Alkaline Lands of the Heihe Middle Reaches. Ecology and Environmental Sciences, 24, 1969-1975. 